\title{
Is There a Regulation in the Expansion of Urban Spatial Structure? Empirical Study from the Main Urban Area in Zhengzhou, China
}

\author{
Yanyan $\mathrm{Wu}$ (1) and Jiadong Yuan *
}

check for updates

Citation: Wu, Y.; Yuan, J. Is There a Regulation in the Expansion of Urban Spatial Structure? Empirical Study from the Main Urban Area in Zhengzhou, China. Sustainability 2022, 14, 2883. https://doi.org/ $10.3390 /$ su14052883

Academic Editor: Wann-Ming Wey

Received: 19 November 2021

Accepted: 28 February 2022

Published: 2 March 2022

Publisher's Note: MDPI stays neutral with regard to jurisdictional claims in published maps and institutional affiliations.

Copyright: (C) 2022 by the authors. Licensee MDPI, Basel, Switzerland. This article is an open access article distributed under the terms and conditions of the Creative Commons Attribution (CC BY) license (https:/ / creativecommons.org/licenses/by/ $4.0 /)$.
School of Geographical Sciences, Northeast Normal University, Changchun 130024, China; wuyy358@nenu.edu.cn * Correspondence: yuanjd703@nenu.edu.cn

\begin{abstract}
The city is a fundamental regional unit of development. Urban spatial structure is a relationship performance among the physical environment, functional activities, and cultural values. Identifying the urban spatial structure and functional areas accurately is of great significance for optimizing urban planning and promoting urban development. Previous studies have focused on the distribution for the single-functional area in some big cities and urban agglomerations from a view of a static time node, with little focus on multifunctional areas' distribution from the perspective of comprehensive evolutionary in underdeveloped regions, especially in provincial capitals in the Central Chinese region. Therefore, taking Zhengzhou, a representative National Central City in the undeveloped central part of China as an example, we investigate urban spatial sprawling in the main urban area. Our interest is twofold. Firstly, we investigate the urban center as to whether, and to what extent, scaling in the spatial structure. The second point of importance concerns the comparison of specific types of functional area in the spatial structure and morphology from a microlevel perspective. The identification framework has been constructed to identify and evaluate the urban spatial structure. The research shows the following: (i) There is a strong correlation between the urban center which is extracted and the density in spatial distribution. The density value of POIs decreases from the urban center to the suburbs. This result is in line with objective facts. (ii) The urban center area has expanded by $25.16 \mathrm{~km}^{2}$ in 2 years. In the center of the main urban area of Zhengzhou, it is generally accepted that the spatial structure pattern monocentric, but is polycentrically patterned in function. The compactness is increasing in the urban center area. (iii) By identifying the mixed functional area, it presents a circle-layer expanded layout with the comprehensive functional area as the core in 2016 and 2018. The comprehensive functional area has developed significantly and maturely, and in the multifunctional area, the development of the publicresidential-business functional area and the public-residential-leisure functional area is relatively mature. In short, this study not only helps strategic planners to strengthen refined management, practical planning, construction, and management integration but also to assess whether policies or actions have been delivered as effectively as planned by identifying the urban spatial structure and revealing the evolution regulation.
\end{abstract}

Keywords: urban spatial structure; urban morphology; points of interest; functional area; urban planning

\section{Introduction}

The formation of urban center and functional area is concerned with the goods production and the markets organization [1]. Studies have found that there is a significant relationship between metropolitan spatial structure and economic development, and the research on this relationship has a long tradition. It is the rational structure that promotes economic development [2,3]. However, in China, this is different from developed countries. There are two main factors influencing the urban structure. One is that the Chinese government plays a leading role in urban planning and development. Another is that the 
spontaneous expansion of the cities is impeded by Chinese unique urban-rural isolation of the secondary land system [4]. Given the growth and complexity in urban areas, exploring the spatial structure development and changes in the main urban areas has always been an important subject in geography and urban planning.

Urban spatial structure is a relationship performance among the physical environment, functional activities, and cultural values [5]. The quality of a structure affects the urban functions. The urban spatial morphology is an external appearance of urban structure, it is a spatial result of various natural, social, and economic factors acting on urban [6]. Understanding how urban structures evolve is the fundamental prerequisite for restructuring their spatial form to plan for ongoing growth [7]. It plays a vital role in exploring the internal development mechanism and realizing the reorganization and optimization in the urban landscape by identifying the urban spatial structure and urban spatial morphology. Urban spatial structure is an important trait for assessing the effects of urban planning. Quantifying urban spatial structure can not only help to identify the problems with current planning but also provide a basic reference for future adjustments.

At present, the study of urban spatial structure and morphology has widely spread; it covers topics from the identification [8,9] and assessment $[10,11]$ to the formation and evolution of the urban spatial structure, etc., [12-14]. In the concept of urban structure, current interpretations can be mainly contained into two types: morphological structure and functional structure [15]. The morphological approach draws on identifying the spatial distribution of dense residential areas or employment areas, but little giving attention to socio-economic activities. In terms of characterizing the urban morphological center structure, there are many indexes used; for example, population size, population density, employment size, road network density, and land use mix, degree, and so on. The methods used to measure morphological center contained descriptive analysis, rank-scale analysis, standard deviation, primacy degree, Gini coefficient [16-18]. In geography and urban planning, the most commonly used approaches include spatial statistics $[19,20]$, spatial clustering [21], exploratory spatial data analysis [22-24]. Some quantitative analysis is used to identify urban spatial forms such as compactness [20,24], fractal methods, and space syntax $[25,26]$.

A morphologically monocentric region can also be a functionally polycentric region, and vice versa [10]. Due to the multiscalar attribute, polycentricity on one scale can lead to monocentricity of another. In contrast to the morphological method, functional center structure pays more attention to describing the patterns of clusters of urban socioeconomic distribution and association.

As an essential part of the urban economic and environmental development, the internal spatial structure of the main urban area can not only reflect the distribution for social and economic development but also predict future development and potential. SoTherefore it is of great significance to promoting and coordinating urban development by exploring the spatial structure and changes in main urban areas. With the development and application of geographic information and technology, multistage data are used widely in the study of identifying urban spatial structure. For instance, identifying urban spatial structure by mobile phone data $[27,28]$, taxi trip data $[9,10,29]$, Weibo sign-in data $[30,31]$, points of interests [32], using DMSP-OLS night-time light [33], and combined multisource data [34-36]. However, in terms of scope and perspective, a lot of studies mainly focus on how to identify urban single-functional areas' distribution and on what the relationship between functional areas, such as jobs-housing spatial distribution, from the view of a static time node, there are few studies drawing on mixed functional areas distribution and from the perspective of comprehensive evolutionary. Further, in study area distribution, a large number of studies concentrated on megacities such as Beijing, Shanghai, Guangzhou, Shenzhen Wuhan and Chongqing [36-38], and some economic belt and agglomeration from a macroscopic view [39-41], while less focusing on general provincial capitals in undeveloped central and western China, especially in the main area of these cities. 
In the Proposals of the Central Committee of the Communist Party of China on Formulating the Fourteenth Five-Year Plan for National Economic and Social Development and the 2035 Vision, the proposal of drawing urban spatial structure reasonably has been put forward. It is representative to choose Zhengzhou as the study area. Zhengzhou, with the highest population density in the Chinese Central Region, is one of the National Central Cities and the core of 'Central Plains Urban Agglomeration'. Therefore, we investigate the complexity in the spatial structure and functional area characters in the main urban area in Zhengzhou based on POIs. Our study can not only reveal the evolution of spatial structure to help strategic planners to strengthen practical management and realize planning, but also assess whether policies or actions have been delivered as effectively as planned. We investigate the distribution regulation of the center and functional area from single functional to comprehensive functional area, from the microcosmic perspective of comprehensive spatiotemporal evolution in the main urban area in Zhengzhou. In addition to supplementing the research gap for researching regions, the study of Zhengzhou's main urban area can be compared with other provincial capital cities such as Taiyuan, Changsha, which provides a reference for urban development in the context of planning.

In this paper, based on the mature method framework and points of interest data, we identify the spatial structure of urban center from the perspective of human activities [14]. The process is as follows. After reviewing the morphological and functional interpretations of urban structure, attention turns to discuss how to characterize the spatial structure and changes. Our interest is twofold. Firstly, identifying centers and characterizing them how and to what extent scaling in the spatial structure. Secondly, identifying all kinds of functional areas and changes. The empirical analysis draws on exploring the structural complexity and the distribution of the functional area in the main urban area in Zhengzhou by using longitudinal data from 2016 and 2018. Then, we discuss the shortcomings in research and put forward research directions for the future. Lastly is the conclusion, summarizing the results and considering the policy implications. Therefore, the primary aims of this paper are to explore how the urban structure evolves in the main urban area of Zhengzhou, as well as examining how structural changes coevolve with strategic planning policies.

\section{Materials and Methods}

\subsection{Study Area}

Zhengzhou city, as the capital city of Henan Province, the core of "Central Plains Urban Agglomeration", a National Central City, has a resident population of 10.14 million. The ratio of urbanization reached $73.37 \%$ in 2018 in Zhengzhou. Zhengzhou has jurisdiction over 6 districts, 5 county-level cities and 1 county. In the earlier round of Zhengzhou urban municipal planning (2010-2020), the urban spatial layout is "one main urban area, one aviation city, two axis and multiple core areas". It proposed to make Zhengzhou be the political, economic, cultural, scientific and educational, comprehensive transportation center, an important and sustainable city in the central region of China. However, in Zhengzhou center's overall conceptual design in 2018, the layout has evolved from "one main urban area and one aviation city" to "Erqi Plaza center and Zhengdong New District two main central area" (http:/ / www.zhengzhou.gov.cn/ (accessed on 9 May 2018)). In this study, we take the main urban area of Zhengzhou as study area, including Zhongyuan District, Erqi District, Guancheng Huizu District, Jinshui District, Huiji District in Figure 1. 

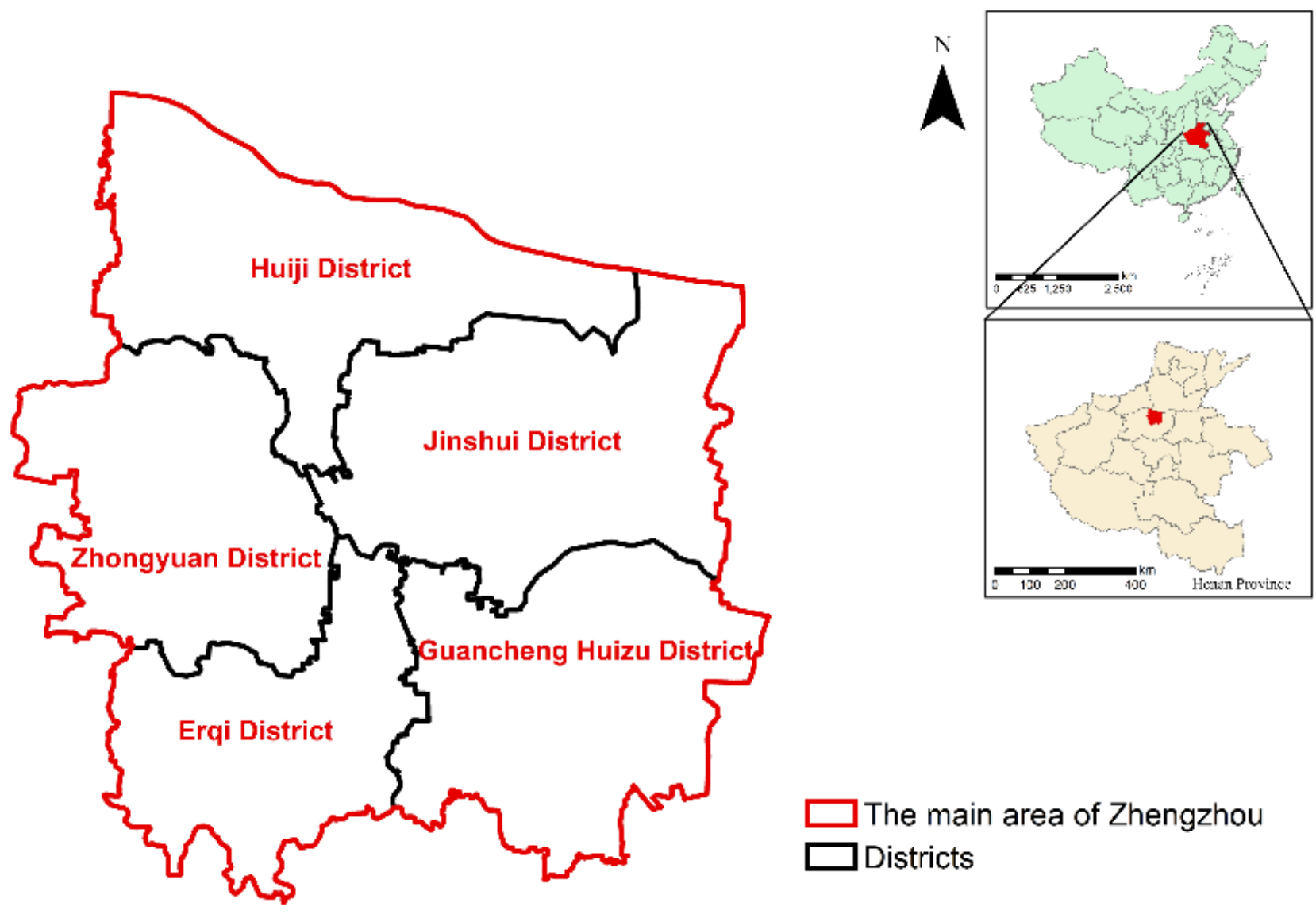

$\square$ The main area of Zhengzhou

$\square$ Districts

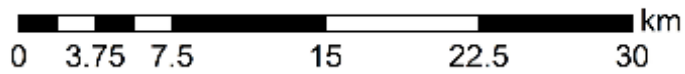

Figure 1. Study area.

Regarding the study of urban spatial structure evolution, megacities such as Beijing, Shanghai, Guangzhou, Shenzhen, Wuhan, Chongqing, and other sites of urban agglomeration have always been the research hotspots in China, while the research on provincial capitals' main urban areas is relatively scarce, especially in central and western China. With the implementation of the "Central Plains Urban Agglomeration" policy, the main urban area of Zhengzhou has achieved rapid development in just a few years, which calls for more research to forecast evolution regulation and analyze influence factors [42-45]. It is of great significance to promote and coordinate urban development by exploring the spatial structure evolution in main urban areas.

\subsection{Data Acquisition}

The points of interest (POIs) data were downloaded from the Resource and Environment Science and Data Center of China (http:/ / www.resdc.cn/ (accessed on 1 May 2021)). The study believes that POIs contain the urban functions totally in the research area [32,45]. The reason is that POIs have the spatial attributes and location information of the urban object entities [46]. A total of 420,025 items (S1 Data) are obtained by collating. Giving the different functions in the urban environment, we integrate and reclassify the data. POIs including public facilities, road ancillary facilities, science and education cultural services, medical facilities, government agencies and social groups, accommodation service, catering services, shopping services, basic life services, recreational spots, sports venues, entertainment venues, villas, residential communities, dormitory buildings, industrial parks, companies and enterprises, financial and insurance, and commercial office buildings constitute the 19 types, which are divided into 5 functional categories, containing pub- 
lic function, living function, leisure function, residential function, and business function (Table 1).

Table 1. POI category and quantity of main area in Zhengzhou in 2018.

\begin{tabular}{cccc}
\hline Category & Quantity $\backslash$ Share & Subcategory & Quantity $\backslash$ Share \\
\hline & & Public facilities & $1722 \backslash 1.22 \%$ \\
Public function & $56,956 \backslash$ & Road ancillary facilities & $15,110 \backslash 10.69 \%$ \\
& $40.30 \%$ & Science and education & $15,870 \backslash 11.23 \%$ \\
& & Medical facilities & $9681 \backslash 6.58 \%$ \\
& & Government agencies and & $8775 \backslash 6.21 \%$ \\
Living function & social groups & $5798 \backslash 4.10 \%$ \\
& & Accommodation services & $24,690 \backslash 17.47 \%$ \\
& $40,106 \backslash$ & Catering services & $1613 \backslash 1.14 \%$ \\
& $28.38 \%$ & Shopping services & $13,803 \backslash 9.77 \%$ \\
& & Basic life services & $578 \backslash 0.41 \%$ \\
Leisure function & Recreation spots & $3332 \backslash 2.36 \%$ \\
& 5344 & Sports venues & $1434 \backslash 1.01 \%$ \\
& $3.78 \%$ & Entertainment venues & $27 \backslash 0.02 \%$ \\
& & Villa areas & $7571 \backslash 5.36 \%$ \\
& & Residential communities & $344 \backslash 0.24 \%$
\end{tabular}

The vector data of administrative boundaries were obtained from the National Platform for Common Geospatial Information Services (https://www.tianditu.gov.cn/, accessed date: 17 July 2021). The map service is open to all users in platform. It contains Zhongyuan District, Erqi District, Guancheng Huizu District, Jinshui District, and Huiji District.

\subsection{Research Methods}

This study has two main objectives: first is to identify the center area in the main urban area in 2016 and 2018; second is to characterize the spatial structure and changes in various types of functional areas. For the first goal, the center is identified from the density of POIs by superposition of the multiple index method. By kernel density estimates in spatial, generating continuous surface of the density in the territory. Then, it has been divided into 10 categories with Natural Breaks (Jenks) (Natural Breaks can maximize the difference between each category) [46]. When the density reaches $80 \%$, the density change is irreversible. So, the area where the density is greater than $80 \%$ is determined as the main urban central area. For the second aim, we firstly defined that the comprehensive functional area contains four and five types of functional area, the multifunctional functional area includes three types of functional area, the bifunctional functional area contains two types of functional area, and the simple functional area has only one type of functional area. Therefore, there are four types of functional area by overlay, including comprehensive functional area, multifunctional functional area, bifunctional functional area, and simple functional area. Then, we characterized functional area spatial structure changes by compaction index, fractal dimension index, and expansion indexes.

\subsubsection{Analyzing Spatial Pattern}

(1) Kernel density estimation (KDE) reflects the distance attenuation affection in spatial distribution and the continuity of different functional areas $[47,48]$. The content is: taking a point of interst [49] as a core, a certain range around is the density calculation range. According to the distance from the center point, all data are given different 
weights. The closer to the center point, the greater the weight. When the distance exceeds a certain value, the nuclear density value is zero.

The KDE equation:

$$
P_{i}=\sum_{i=1}^{n} \frac{1}{\pi r^{2}} \varphi\left(\frac{d_{i s}}{r}\right)
$$

where $P_{i}$ is the value of kernel density estimate, $r$ is radius, $n$ is the points number, $d_{i s}$ is the distance from $i$ to $s, \varphi$ is the distance weight. In this study, we choose 1000 meters' radius by comparing and calculating, which can better reveal the distribution.

(2) Urban spatial form index: The evolution of urban spatial formation can be described by compaction index (CI) and fractal dimension index (DI) [25,50]. Compactness could reflect the spatial and functional characteristics of urban land-use efficiency. It can be used to prevent urban sprawl. The greater the compactness index, the more efficient the land use. The range of the compactness index is from 0 to 1 . When the area is a round, the CI reaches 1 , which is the most compact shape.

The fractal dimension index is used to express the complexity and stability of the landscape types. The larger the fractal dimension index, the more complex the landscape type, the lower the corresponding stability. When the fractal dimension index is close to 1.5 , it means that the landscape type is in a random state similar to Brownian motion, that is, it tends to be in an unstable state. Giving the urban area in the study is spotted in two-dimensions, the range of fractal dimension index is from 1 to 2 , theoretically.

$$
\begin{gathered}
C I=\frac{2 \sqrt{\pi A}}{P} \\
D I=\frac{2 \operatorname{Ln}(0.25 P)}{\operatorname{Ln}(A)}
\end{gathered}
$$

In Equations (2) and (3), where $C I$ is the compaction index, $A$ is the functional area $\left(\mathrm{km}^{2}\right), P$ is the perimeter $(\mathrm{km})$.

\subsubsection{Analyzing Spatiotemporal Expansion}

The expansion speed index (ESI) and the expansion intensity index (EII): ESI is the absolute increase in the expansion of the functional area. The purpose of EII is to compare the expansion speed [25].

$$
\begin{gathered}
E S I=\frac{F A_{n+i}-F A_{i}}{n} \\
E I I=\frac{F A_{n+i}-F A_{i}}{n F A} \times 100 \%
\end{gathered}
$$

In Equations (4) and (5), where $E A_{n+i}$ and $E A_{i}$ represent the functional area, $n$ is the number of years.

\section{Results}

\subsection{Identification Center Spatial Structure and Morphology}

The results show that the urban area of Zhengzhou in 2016 represents polycentricity obviously, however, it has evolved into a huge single center in 2018 (Figure 2).

- Number of urban centers. As can be seen from Figure 2, in the point density map, the number of urban centers in Zhengzhou's main area was 8 in 2016, while the number of urban centers in Zhengzhou main area was 1 large-scale area in 2018;

- Size of urban center. This can refer to the land use scale, which is identified when density reaches $80 \%$ by Natural Breaks (Jenks). This is compared to the size of the centers in 2016 and 2018, as shown in in Figure 2 and Table 2. The urban center size identified in 2016 was $55.59 \mathrm{~km}^{2}$, which accounts for $3.639 \%$ of the main urban area, reaching $80.77 \mathrm{~km}^{2}$ in 2018 , which accounts for $5.288 \%$. 


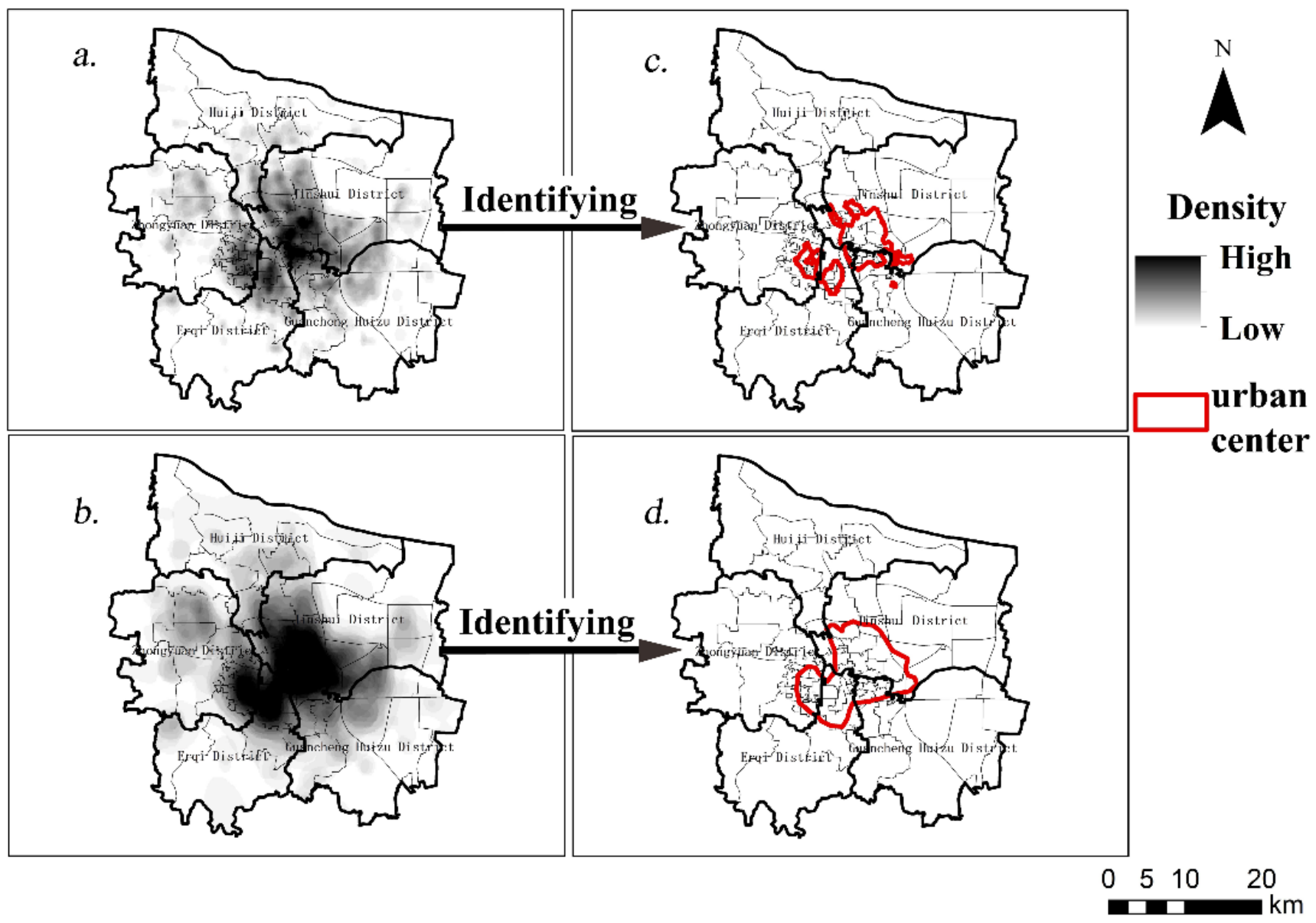

Figure 2. Identification of urban centers in Zhengzhou's main urban areas. ((a,b) are the didstribution of Kernel density estimation; (c,d) are the distribution of urban centers).

Table 2. Statistics about functional area of the main area in Zhengzhou.

\begin{tabular}{|c|c|c|c|c|c|c|c|c|}
\hline \multicolumn{2}{|l|}{ Items } & Years & Public & Living & Leisure & Residential & Business & $\begin{array}{l}\text { Center } \\
\text { Region }\end{array}$ \\
\hline \multirow{2}{*}{\multicolumn{2}{|c|}{ Number of centers }} & 2016 & 8 & 14 & 3 & 3 & 3 & 8 \\
\hline & & 2018 & 2 & 3 & 1 & 2 & 2 & 1 \\
\hline \multirow{2}{*}{\multicolumn{2}{|c|}{ Size }} & 2016 & 8.5306 & 3.8296 & 12.1334 & 34.5624 & 21.8415 & 55.5875 \\
\hline & & 2018 & 43.1852 & 28.7879 & 58.7992 & 50.8000 & 35.5559 & 80.7734 \\
\hline \multirow{4}{*}{ Spatial pattern } & \multirow{2}{*}{ CI } & 2016 & 0.3514 & 0.2576 & 0.5222 & 0.3728 & 0.5048 & 0.3153 \\
\hline & & 2018 & 0.6066 & 0.4737 & 0.8207 & 0.6285 & 0.5833 & 0.6263 \\
\hline & \multirow{2}{*}{ DI } & 2016 & 1.8631 & 2.8401 & 1.4238 & 1.4888 & 1.3650 & 1.5144 \\
\hline & & 2018 & 1.2014 & 1.3729 & 1.0377 & 1.1750 & 1.2342 & 1.1581 \\
\hline \multirow{2}{*}{$\begin{array}{l}\text { Spatiotemporal } \\
\text { expansion }\end{array}$} & $E S I$ & 17.3273 & 12.4792 & 23.3329 & 8.1188 & 6.8572 & 12.5930 & 17.3273 \\
\hline & EII & 2.0312 & 3.2586 & 1.9230 & 0.2349 & 0.3140 & 0.2265 & 2.0312 \\
\hline
\end{tabular}

- Spatial pattern. The main types of urban land expansion contained infill, extension, corridor and satellite cities [49]. The formation of the spatial characteristics of urban land is the result of the interaction of these four effect types collectively, while the urban morphology is the result of the spatial expansion. In the central area, it appears as infill and extension together. The compaction index $(\mathrm{CI})$ and the fractal dimension index (DI) are important in reflecting the spatial pattern. The CI increased from 0.315 (2016) to 0.626 (2018). The increase in compactness reached $98.73 \%$. This indicates that the degree of land intensification is growing in the central area and the internal stability is 
well-founded. Considering that Zhengzhou has a large population and rapid economic and social development, it is more conducive to sustainable development that the spatial pattern tends to be compact than loose. The DI dropped from 1.514 to 1.158 , lower than the average (1.336). With the decline of overall fractal dimension index, the central area tends to be compact.

- Spatiotemporal expansion. With rapid economic development and urbanization, the center of the main urban area of Zhengzhou is expanding continuously. It expanded by $25.18 \mathrm{~km}^{2}$ in the years studied, with an expansion speed of $12.59 \mathrm{~km}^{2}$ per year and an expansion intensity is 0.23 .

\subsection{Identification of Functional Area Spatial Structure and Morphology}

In this section, we identified the distribution of five functional areas respectively and recognized the comprehensive functional area, the multifunctional functional area, the bifunctional functional area, and the simple functional area by superimposing them. We defined that the comprehensive functional area contains four or five types of mixed functional area, the multifunctional functional area includes three types of mixed functional area, the bifunctional area contains two types of functional area, and the simple functional area has only one functional area.

\subsubsection{Identifying Five Simple Functional Area}

Concerning the regarding existing research on the identification of commercial centers, the functional areas can be divided $[48,49]$. The results of five simple functional areas in Zhengzhou's main urban area are shown in Figure 3. It contains five types of functional areas: public functional area, living functional area, leisure functional area, residential functional area, and business functional area [45,47-49].

In terms of center number (Table 2), the polycentricity of various functional areas is more obvious in 2016 than in 2018. In functional area scale, the size of the living functional area was $3.829 \mathrm{~km}^{2}$ in 2016, which was the smallest. The size of the residential functional area was $34.562 \mathrm{~km}^{2}$, which was the largest. The area of the residential functional area was 8.03 times larger than the living function. The sizes of public functional area, leisure functional area, and business functional area were $8.531 \mathrm{~km}^{2}, 12.133 \mathrm{~km}^{2}$, and $21.842 \mathrm{~km}^{2}$, respectively. In 2018, the size of the leisure functional area was $58.799 \mathrm{~km}^{2}$, which was the largest. The size of public functional area, living functional area, residential functional area, and business functional area were $43.185 \mathrm{~km}^{2}, 28.788 \mathrm{~km}^{2}, 50.800 \mathrm{~km}^{2}$, and $35.556 \mathrm{~km}^{2}$, respectively.

In terms of spatial pattern (Table 2), the compactness improved generally in 2018. In particular, the compactness of the leisure functional area improved obviously. The fractal dimension generally dropped in 2018, and the dimension of the living functional area dropped from 2.8401 to 1.3729 . The exact value of compactness and dimension of various functional area types is shown in Table 2. It shows that the development of various types of functional areas tends to be more compact.

In terms of spatiotemporal expansion (Table 2), the leisure functional area had the fastest expansion speed at $23.333 \mathrm{~km}^{2}$ per year, and the living functional area had the largest expansion intensity with an intensity value of 3.259. The residential functional area was the smallest in terms of expansion speed and intensity. 


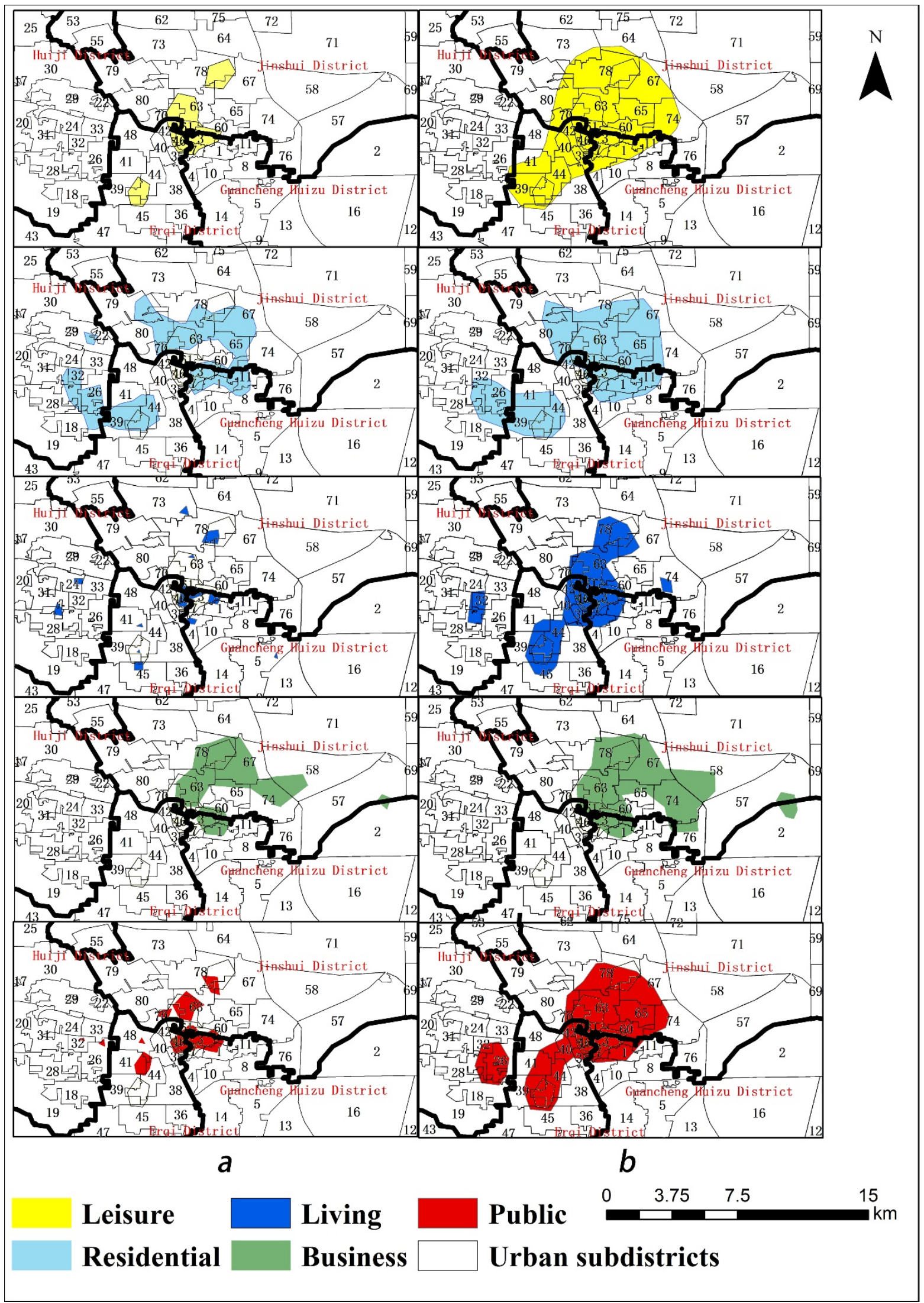

Figure 3. Identification of five simple functional areas in 2016 (a) and 2018 (b). 


\subsubsection{Centers Tracking of Functional Areas}

To identify the spatiotemporal distribution of various functional areas, we measured the center of gravity and location shift of five types functional area in Figure 4. It shows center tracking from 2016 to 2018 . The comprehensive center moved $1.868 \mathrm{~km}$ to the northeast, the public center moved $1.372 \mathrm{~km}$ to the southwest, the living center moved $1.814 \mathrm{~km}$ to the south, the leisure center moved $0.798 \mathrm{~km}$ to the southwest, the residential center moved $1.759 \mathrm{~km}$ to southeast, the business center moved $1.899 \mathrm{~km}$ to the east. In short, the comprehensive and public centers tended to move southwest, while the leisure and living centers tended to the north, and the residential and business centers tended to east. The farthest moving distance was the business center, which was $1.899 \mathrm{~km}$. The smallest distance was the leisure center, which was $0.798 \mathrm{~km}$.

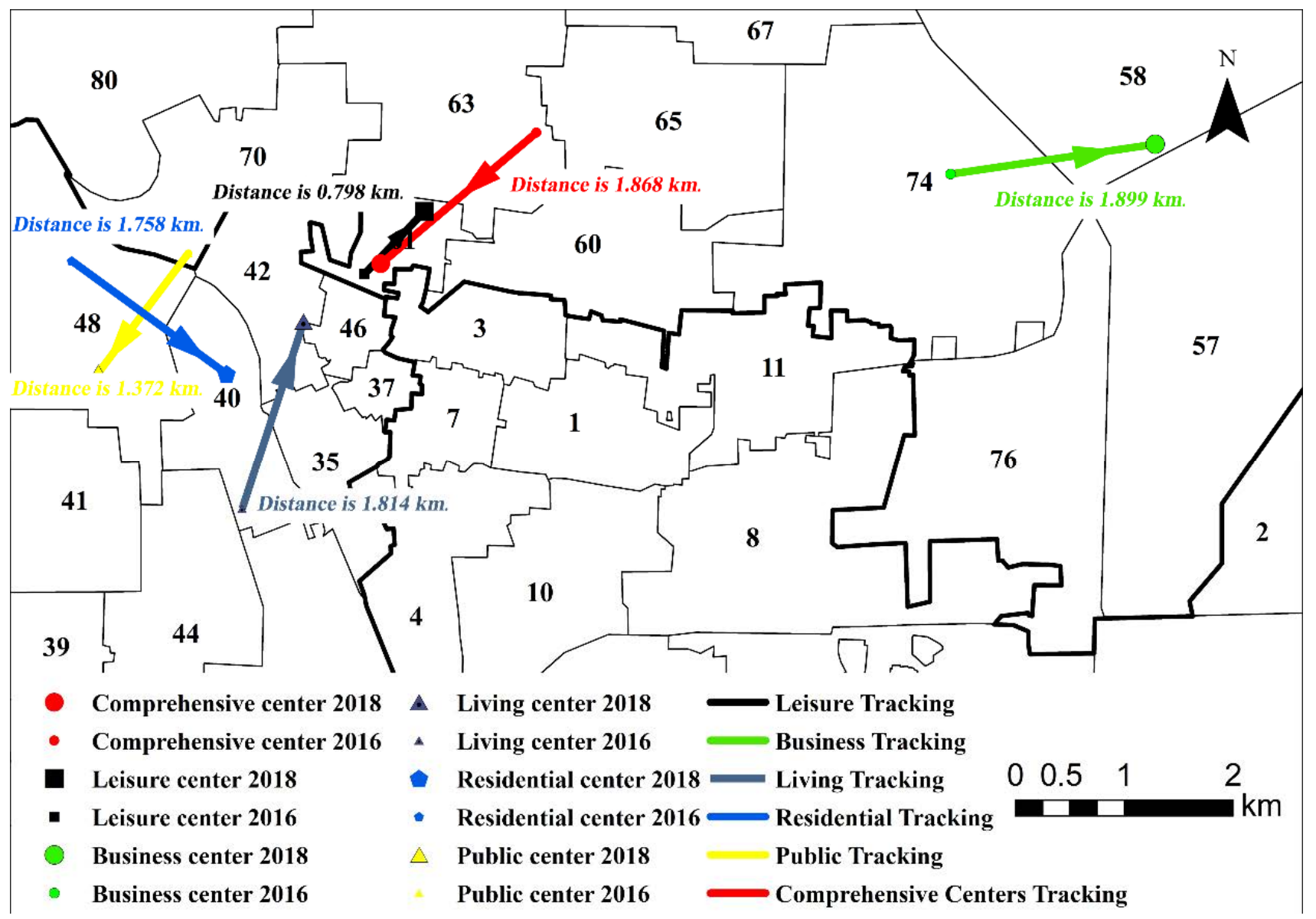

Figure 4. Center tracking from 2016 to 2018.

\subsubsection{Identifying Mixed Functional Area}

There are four types functional area by overlay, including comprehensive functional area, multifunctional functional area, bifunctional functional and simple functional area, as shown in Figure 5 and Table 3. 

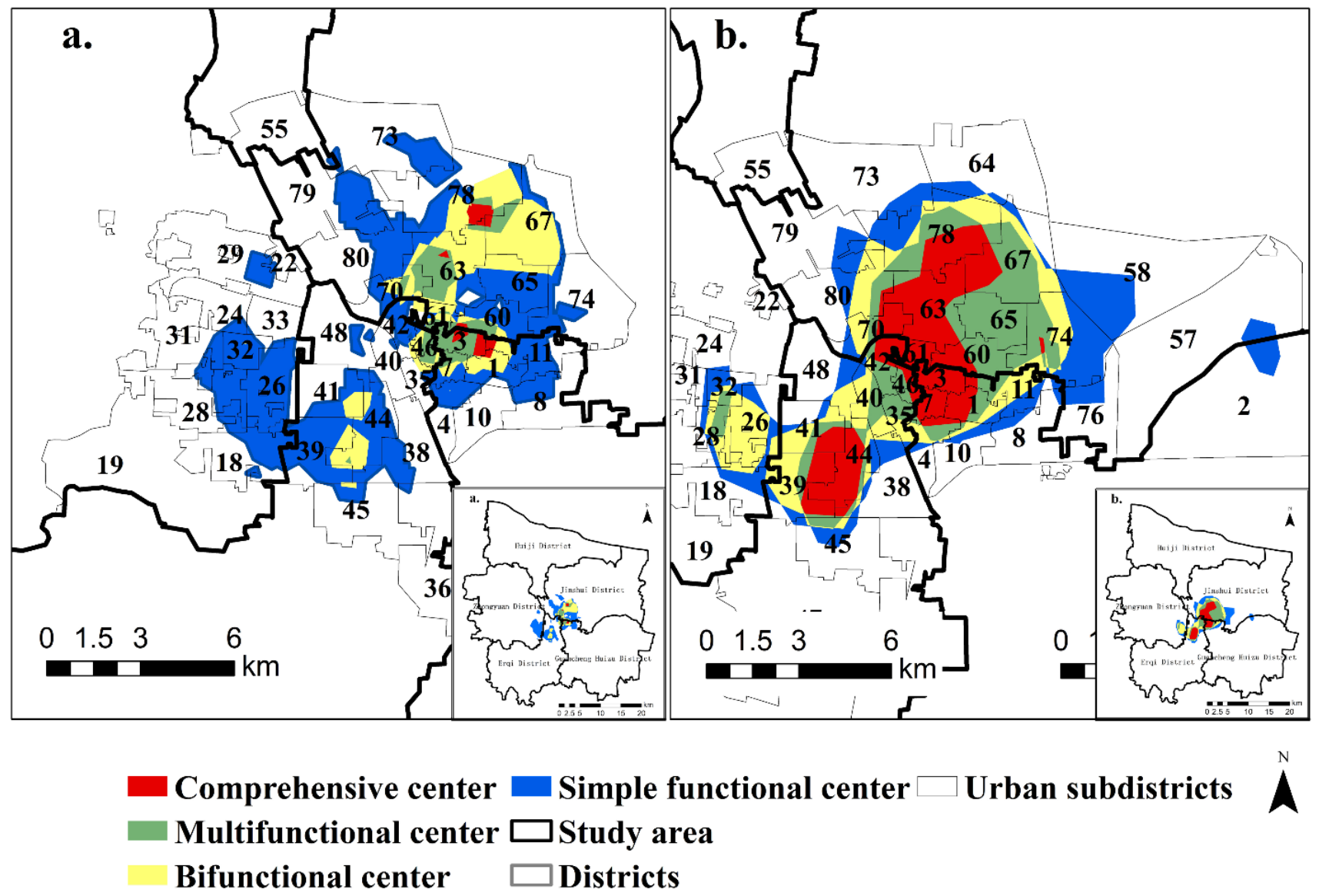

Figure 5. Distribution of the various functional areas in 2016 (a) and 2018 (b).

Table 3. Statistics about the mixed functional area.

\begin{tabular}{cccccc}
\hline \multirow{2}{*}{ Items } & Years & $\begin{array}{c}\text { Comprehensive } \\
\text { Area }\end{array}$ & $\begin{array}{c}\text { Multifunctional } \\
\text { Area }\end{array}$ & $\begin{array}{c}\text { Bifunctional } \\
\text { Area }\end{array}$ & $\begin{array}{c}\text { Simple } \\
\text { Functional Area }\end{array}$ \\
\hline \multirow{2}{*}{ Center size } & 2016 & 1.1854 & 5.0647 & 13.3834 & 35.9540 \\
& 2018 & 19.5947 & 19.7544 & 18.1590 & 23.2653 \\
\hline Spatial pattern (CI) & 2016 & 0.4567 & 0.2946 & 0.2174 & 0.1848 \\
& 2018 & 0.5469 & 0.2319 & 0.1806 & 0.1735 \\
\hline Spatiotemporal & 9.2047 & 7.3449 & 2.3878 & -6.3444 & -6.8572 \\
expansion & 3.8825 & 0.7251 & 0.0892 & -0.0882 & -0.3140 \\
\hline
\end{tabular}

The center size of the simple functional area was $35.954 \mathrm{~km}^{2}$, which made up the largest proportion of the total $(64.680 \%)$. The area of comprehensive functional area was $1.185 \mathrm{~km}^{2}$, which was the smallest proportion (2.132\%) in 2016. In 2018, the area of the four types of functional area increased, and the area gap narrowed gradually, but the largest proportion was the simple functional area, as before. The area of comprehensive functional, multifunctional functional, bifunctional functional and simple functional were $19.594 \mathrm{~km}^{2}, 19.754 \mathrm{~km}^{2}, 18.159 \mathrm{~km}^{2}$ and $23.265 \mathrm{~km}^{2}$, respectively, in 2018 . Regarding spatial pattern, it presented as a circle-layer expanded layout with the comprehensive functional area as a core in both 2016 and 2018. The compactness of the comprehensive functional area increased, while the others decreased, especially in multifunctional center, which dropped 0.063 in 2 years. In terms of spatiotemporal expansion, the development of the comprehensive functional area, multifunctional functional area, and bifunctional area manifested a state of expansion. The comprehensive functional area was the fastest expanding, followed by multifunctional area; however, the simple functional area shrunk. 
The distribution of simple-mixed functional areas in 2018 are taken as an example in Figure 6. It presents a circle-layer expanded layout with the comprehensive functional area as a core. The center area contained two types of comprehensive functional area (ABCDE, $\mathrm{ABCD}$ ), the area of which was $19.594 \mathrm{~km}^{2}$; nine types of multifunctional area (ACE, ABE, $\mathrm{ACD}, \mathrm{ADE}, \mathrm{ABD}, \mathrm{ABC}, \mathrm{CDE}, \mathrm{BDE}, \mathrm{BCD})$, is the area of which was $19.754 \mathrm{~km}^{2}$; seven types of bifunctional area $(\mathrm{AC}, \mathrm{AD}, \mathrm{BC}, \mathrm{BD}, \mathrm{CD}, \mathrm{DE}, \mathrm{AB})$, is the area of which was $18.159 \mathrm{~km}^{2}$; and five simple functional area $(A, B, C, D, E)$, the area of which was $23.265 \mathrm{~km}^{2}$.

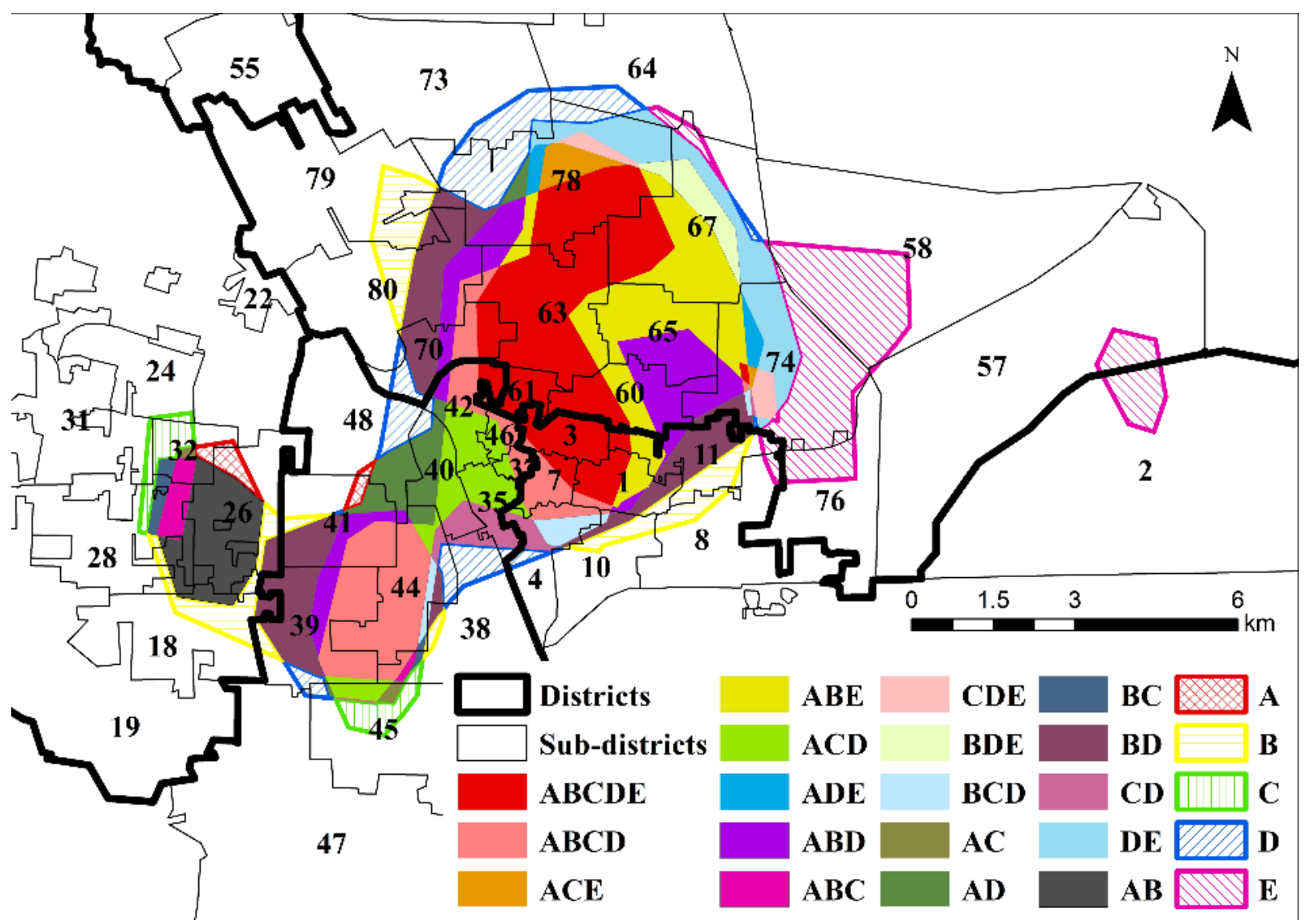

Figure 6. The distribution of simple-mixed functional areas in 2018: (A) is the public functional area; (B) is the residential functional area; (C) is the living functional area; (D) is the leisure functional area; and $(\mathrm{E})$ is the business functional area.

In the comprehensive functional area, the area was $19.594 \mathrm{~km}^{2}$, and it contained a public-residential-living-leisure-business functional area and a public-residential-livingleisure functional area. The public-residential-living-leisure-business functional area was $12.217 \mathrm{~km}^{2}$, which accounted for $62.37 \%$ of the total, distributed across eight subdistricts: south of Culture Street block (78), west of Fengchan Street block (67), Jingbalu Street block (63), Duling block (61), west of People Street block (60), North Xiajie Avenue block (3), northwest of East Avenue block (1), northeast of West Avenue block (7). The four types mixed formed the public-residential-living-leisure functional area, making up $7.370 \mathrm{~km}^{2}$, distributing southeast of Daxue Street block (41), east of Huaihe Street block (39) and Jianzhong Avenue Block (44). Comparing the result with the urban planning, it is exactly the extended range of the main center of Erqi square (for the reference number, see Appendix A).

The multifunctional area is mainly based on a public-residential-business functional area and a public-residential-leisure functional area. It presents as a circle-layer with the comprehensive functional area. The distribution characteristics of the multifunctional area is disordered, showing largely mixed and gathering settlements, mainly including a large 
proportion of Culture Street block (78) and Fengchan Street block (67), People Street block (60) and Huayuan Street block (65). It corresponds to the sub-center range of Huayuan Street in urban planning.

In bifunctional area, the largest area is the residential-leisure functional area, followed by the business-leisure functional area, and the public- residential functional area, which account for $39.192 \%, 20.580 \%$, and $18.140 \%$, respectively.

The simple functional area is scatters at the outermost periphery, which is dominated by the business functional area and leisure functional area distributing on the east and northern fringe, respectively. Moreover, the business functional area is in Zhengdong New District and an enclave in the junction of the Shangdu Street block (2) and Jicheng Street block (57). These two area types distribute independently, related to their characteristics. For example, the business functional area has a larger area and a quiet environment, so it is less mixed with other land. The same goes for the leisure functional area, as it occupies a large area and is largely affected by land price. The public and living functional areas arealso small, showing that the single public and living functional area is rare in the periphery, and it is mostly mixed with others.

\section{Discussion}

This study uses POIs to characterize the urban spatial structure in a typical city, Zhengzhou, and to explore the various functional areas on the block level. In terms of data sources and applications, firstly, the study holds that identifying urban structure and functional area by POIs avoided the subjective nature of data in some previous research, which makes the recognition more credible and accurate. Secondly, compared with traditional departmental statistics, the full-sample POIs data provides the spatial location of various entities in urban area, and so can overcome the problem of refined insufficiency in traditional functional area. In addition to assessing the distribution of urban resources by various functional areas, it provides a basis for optimization resource allocation. For example, the study found some problems in the distribution. The expansion speed of the leisure functional area was significantly higher than others, showing an immature developmental phenomenon. However, the result is in line with the actual situation and planning of creating a special functional zone for the development of municipal and provincial civil culture and exhibition functional area in Huiji District [45].

There are still some deficiencies in this research, and we should continue to improve them. First of all, it is diversity in data selection. For example, taxi trips, smart cards, nighttime lights, mobile phone signaling, and remote sensing classification can be used to identify urban structure $[8-10,14,29]$. Secondly, the choice of the year may have an impact on the results of the study. In this study, we had a 2-year time span, which is relatively short for the "evolution" of the urban spatial structure. In the future, we would aim to acquire multiperiod and multivariate data to make fusion and comparative analysis in the following study. We focused on identifying the evolution of the urban spatial structure and functional area, and the shortcomings will be adequate in the future.

As the capital of Henan province, Zhengzhou has advantages in policies, economy, and transportation. In addition, the increasing population in urban area has promoted the expansion of various functional areas rapidly. Especially in the main central urban area, the demand for basic industrial, commercial and residential area growth, as well as the improvement of urban infrastructure construction and traffic conditions, promoting the speed of accelerating development and the degree of complexity in the comprehensive multifunctional functional areas. The socioeconomic driving forces in urbanization (e.g., investment, employment) are undoubtedly important factors for urban expansion. However, compared with Beijing, Shanghai, Guangzhou, and Shenzhen, Zhengzhou's central urban expansion speed is slower, and the expansion intensity is lower [48,51]. In addition, it is important to consider the effect that policy support and orientation has in promoting the urban spatial layout, such as that of the Zhengdong New District. The form of POI density shows a "staircase" decaying mode from the urban center to outside. In the urban center, 
the various elements are concentrated, which encourages efficient land use. In expansion, hierarchical differences appear gradually. With the construction of mixed functional area, it is necessary to take advantage of each functional area to improve urban land use efficiency and achieve coordinated development.

\section{Conclusions}

This study analyzed urban spatial expansion in the central and functional areas by taking the main urban area of Zhengzhou as an example based on POIs data. It showed that: (i) In spatial distribution, there has a strong correlation between the urban center which is extracted by the KDE method and the high density value. The density values decrease from the urban center to the suburbs. This result is in line with the objective facts. (ii) The urban center area has expanded by $25.16 \mathrm{~km}^{2}$ in 2 years. It tends to monocentricity in terms of spatial pattern, but polycentricity in function in the center of the main urban area of Zhengzhou. (iii) The compactness index of urban center and the five types simple functional area are increasing. In terms of spatiotemporal expansion, the fractal dimension index of the urban center and the five simple functional areas fell simultaneously. The degree of land intensification grew in the main urban area and the internal stability is wellfounded. In addition, the aggregating spatial features of the five types of functional areas are different. The leisure functional area had the fastest expansion speed, and the living functional area had the largest expansion intensity. (iv) In center tracking of the functional areas from 2016 to 2018, the points of the leisure center, residential center, and business center moved to the east, while the points of the comprehensive center and public center moved to the southwest. (v) We identified the mixed functional area, which presented as a circle-layer expanded layout with the comprehensive functional area as the core in both 2016 and 2018. The comprehensive functional area significantly maturely developed, and in the multifunctional area, the development of public-residential-business functional area and public- residential-leisure functional areas matured, relatively. The comprehensive functional area had the fastest expansion, and the multifunctional area followed. The simple functional area shrank.

These changes conform with the ideal goal of "building the main urban area into a comprehensive development zone". Spatially, the comprehensive functional area was mainly distributed in Guancheng Huizu District, Jinshui District, and the multifunctional area was distributed mainly in Erqi District. Overall, the results of functional distribution analysis based on the POI data will have a positive influence on creating a suitable environment for business, livability, leisure and communication for urban planning. It can provide a basis for further optimizing the spatial layout. Zhengzhou is moving towards being more polycentric in function and compact in pattern in terms of its urban structure.

Author Contributions: Methodology, formal analysis, investigation, and original draft preparation, Y.W. and J.Y.; supervision, J.Y.; review and editing, Y.W.; data preparation, Y.W. and J.Y. All authors have read and agreed to the published version of the manuscript.

Funding: This work has been supported by the National Natural Science Foundation of China (Nos. 40371040).

Data Availability Statement: http://www.resdc.cn/ (accessed on 9 May 2018); https://www. tianditu.gov.cn/ (accessed on 1 May 2021).

Conflicts of Interest: The authors declare no conflict of interest. 


\section{Appendix A}

Table A1. Administrative area code.

\begin{tabular}{|c|c|c|c|c|c|}
\hline Code. & Name & Code & Name & Code & Name \\
\hline 1 & East Avenue Block & 32 & Jianshe Street Block & 57 & Jicheng Street Block \\
\hline 2 & $\begin{array}{l}\text { Shangdu Street } \\
\text { Block }\end{array}$ & 33 & $\begin{array}{l}\text { Mianfang Street } \\
\text { Block }\end{array}$ & 58 & Ruyihu Block \\
\hline 3 & $\begin{array}{c}\text { North Xiajie Avenue } \\
\text { Block }\end{array}$ & 35 & YIma Street Block & 60 & People Street Block \\
\hline 4 & Nanguan Block & 36 & $\begin{array}{c}\text { Jingguang Street } \\
\text { Block }\end{array}$ & 61 & Duling Block \\
\hline 7 & West Avenue Block & 37 & Dehua Avenue Block & 63 & Jingbalu Street Block \\
\hline 8 & Erligang Block & 38 & Fuhua Avenue Block & 64 & Beilin Street Block \\
\hline 10 & Longhai Street Block & 39 & Huaihe Street Block & 65 & $\begin{array}{c}\text { Huayuan Street } \\
\text { Block }\end{array}$ \\
\hline 11 & $\begin{array}{l}\text { Chengdong Street } \\
\text { Block }\end{array}$ & 40 & Mifengzhang Block & 67 & $\begin{array}{c}\text { Fengchan Street } \\
\text { Block }\end{array}$ \\
\hline 18 & Ruhe Street Block & 41 & Daxue Street Block & 70 & Dashi Bridge Block \\
\hline 19 & $\begin{array}{c}\text { Hanghai West Street } \\
\text { Block }\end{array}$ & 42 & $\begin{array}{l}\text { Minggong Street } \\
\text { Block }\end{array}$ & a73 & $\begin{array}{c}\text { Dongfeng Street } \\
\text { Block }\end{array}$ \\
\hline 22 & $\begin{array}{l}\text { Zhongyuan West } \\
\text { Street Block }\end{array}$ & 44 & $\begin{array}{c}\text { Jianzhong Avenue } \\
\text { Block }\end{array}$ & 74 & Weilai Street Block \\
\hline 24 & Qinling Street Block & 45 & Yangtze Street Block & 76 & $\begin{array}{c}\text { Fenghuangtai Street } \\
\text { Block }\end{array}$ \\
\hline 26 & Linshanzhai Block & 46 & Jiefang Street Block & 78 & Culture Street Block \\
\hline 28 & Lvdong Town Block & 47 & $\begin{array}{c}\text { Songshan Street } \\
\text { Block }\end{array}$ & 79 & New Nanyang Block \\
\hline 29 & Tongbai Street Block & 48 & Wulibao Block & 80 & $\begin{array}{l}\text { Nanyang Street } \\
\text { Block }\end{array}$ \\
\hline 31 & Sanguanmiao Block & 55 & Liuzhai Block & & \\
\hline
\end{tabular}

\section{References}

1. Parr, J.B. The Regional Economy, Spatial Structure and Regional Urban Systems. Reg. Stud. 2014, 48, 1926-1938. [CrossRef]

2. Gordon, P.; Richardson, H.W. Are compact cities a desirable planning goal? J. Am. Plan. Assoc. 1997, 63, 95-106. [CrossRef]

3. Yao, X.; Zeng, J.; Li, W. Spatial correlation characteristics of urbanization and land ecosystem service value in Wuhan Urban Agglomeration. Trans. Chin. Soc. Agric. Eng. 2015, 31, 249-256. [CrossRef]

4. Zhao, S.; Zhou, D.; Zhu, C.; Sun, Y.; Wu, W.; Liu, S. Spatial and Temporal Dimensions of Urban Expansion in China. Environ. Sci. Technol. 2015, 49, 9600-9609. [CrossRef]

5. Zhou, C.; Ye, C. Progress on studies of urban spatial structure in China. Prog. Geogr. 2013, 32, 1030-1038. [CrossRef]

6. Song, Y.; Wang, S.; Ye, Q.; Wang, X. Urban Spatial Morphology Characteristic and Its Spatial Differentiation of Mining City in China. Areal Res. Dev. 2012, 31, 45-49.

7. Bogart, W.T. Don't Call It Sprawl: Metropolitan Structure in the 21st Century; Cambridge University Press: Cambridge, UK, 2006.

8. Tu, W.; Hu, Z.; Li, L.; Cao, J.; Jiang, J.; Li, Q.; Li, Q. Portraying Urban Functional Zones by Coupling Remote Sensing Imagery and Human Sensing Data. Remote Sens. 2018, 10, 141. [CrossRef]

9. Li, H.; Xu, X.; Li, X.; Zhang, H. Characterizing the urban spatial structure using taxi trip big data and implications for urban planning. Front. Earth Sci. 2021, 15, 70-80. [CrossRef]

10. Zhang, Y.; Marshall, S.; Cao, M.; Manley, E.; Chen, H.F. Discovering the evolution of urban structure using smart card data: The case of London. Cities 2021, 112, 103157. [CrossRef]

11. Liao, Y.J.; Zhao, H.T.; Jiang, Y.; Ma, Y.K.; Luo, X.; Li, X.Y. An innovative method based on cloud model learning to identify high-risk pollution intervals of storm-flow on an urban catchment scale. Water Res. 2019, 165, 115007. [CrossRef]

12. Hui, E.C.M.; Li, X.; Chen, T.T.; Lang, W. Deciphering the spatial structure of China's megacity region: A new bay area-The Guangdong-Hong Kong-Macao Greater Bay Area in the making. Cities 2020, 105, 102168. [CrossRef]

13. Hu, L.; Sun, T.; Wang, L. Evolving urban spatial structure and commuting patterns: A case study of Beijing, China. Transp. Res. Part D Transp. Environ. 2018, 59, 11-22. [CrossRef]

14. Lou, G.; Chen, Q.; He, K.; Zhou, Y.; Shi, Z. Using Nighttime Light Data and POI Big Data to Detect the Urban Centers of Hangzhou. Remote Sens. 2019, 11, 1821. [CrossRef]

15. Green, N. Functional Polycentricity: A Formal Definition in Terms of Social Network Analysis. Urban Stud. 2007, 44, 2077-2103. [CrossRef] 
16. Burger, M.; Meijers, E. Form follows function? Linking morphological and functional polycentricity. Urban Stud. 2012, 49, 1127-1149. [CrossRef]

17. Liu, X.; Derudder, B.; Wang, M. Polycentric urban development in China: A multi-scale analysis. Environ. Plan. B Urban. Anal. City Sci. 2017, 45, 953-972. [CrossRef]

18. Adolphson, M. Estimating a polycentric urban structure. Case study: Urban changes in the Stockholm Region 1991-2004. J. Urban Plan. Dev. 2009, 135, 19-30. [CrossRef]

19. McMillen, D.P. Nonparametric Employment Subcenter Identification. J. Urban Econ. 2001, 50, 448-473. [CrossRef]

20. Marshall, S.; Gong, Y.; Green, N. Urban Compactness: New Geometric Interpretations and Indicators. In The Mathematics of Urban Morphology; D'Acci, L., Ed.; Birkhäuser: Cham, Switzerland, 2019. [CrossRef]

21. Vasanen, A. Functional Polycentricity: Examining Metropolitan Spatial Structure through the Connectivity of Urban Sub-centres. Urban Stud. 2012, 49, 3627-3644. [CrossRef]

22. Liu, X.; Wang, M. How polycentric is urban China and why? A case study of 318 cities. Landsc. Urban Plan. 2016, 50, 10-20. [CrossRef]

23. Arribas-Bel, D.; Sanz-Gracia, F. The validity of the monocentric city model in a polycentric age: US metropolitan areas in 1990, 2000 and 2010. Urban Geogr. 2014, 35, 980-997. [CrossRef]

24. Li, Y.; Xiong, W.; Wang, X. Does polycentric and compact development alleviate urban traffic congestion? A case study of 98 Chinese cities. Cities 2019, 88, 100-111. [CrossRef]

25. Zhang, Z.; Jia, D.; Deng, S.; Jin, X. Quantitative Research of Urban Spatial Morphology: A Case Study of the Main Urban Zone of Chongqing. J. Geo-Inf. Sci. 2013, 15, 297-306. [CrossRef]

26. Wang, H.; Zhou, K. Review of urban form, structure and morphology in China during 2003-2013. Prog. Geogr. 2014, 33, 689-701. [CrossRef]

27. Niu, X.; Ding, L.; Song, X. Understanding urban spatial structure of Shanghai central city based on mobile phone data. China City Plan. Rev. 2015, 24, 15-23.

28. Xiao, D.; Zhang, X.; Hu, Y. Urban Functional Area Identification Method Based on Mobile Big Data. J. Syst. Simul. 2019, 31, 2281-2288. [CrossRef]

29. Liu, X.; Gong, L.; Gong, Y.; Liu, Y. Revealing travel patterns and city structure with taxi trip data. J. Transp. Geogr. 2015, 43, 78-90. [CrossRef]

30. Kang, L.; Liu, H.; Chen, X.; Li, J.; Li, J. A Research on the Complexity of Urban Functional Areas Based on Weibo Sign-in Data. Geomat. Spat. Inf. Technol. 2021, 44, 38-40.

31. Song, C.; Pei, T. Exploring Polycentric Characteristic and Residential Cluster Patterns of Urban City from Big Data. J. Geo-Inf. Sci. 2019, 21, 384-397. [CrossRef]

32. Xue, B.; Zhao, B.; Xiao, X.; Li, J.; Xie, X.; Ren, W. A POI Data-based Study on Urban Functional Areas of the Resources-based City: A Case Study of Benxi, Liaoning. Hum. Geogr. 2020, 35, 81-90. [CrossRef]

33. Bergantino, A.S.; Di Liddo, G.; Porcelli, F. Regression-based measure of urban sprawl for Italian municipalities using DMSP-OLS night-time light images and economic data. Appl. Econ. 2020, 52, 4213-4222. [CrossRef]

34. Mao, S.; Jiao, L.; Xu, G.; Li, Z. Identification of the polycentric spatial structure in Wuhan City based on multisource data. Prog. Geogr. 2019, 38, 1675-1683. [CrossRef]

35. Chen, B.; Xu, S.; Zhou, Y.; Xu, F.; Wang, H. Analysis of urban spatial structure based on spatial coupling between POI and nighttime data: A case study of main urban region in Wuhan. Bull. Surv. Mapp. 2020, 70-75. [CrossRef]

36. Yue, J.; Chen, X.; Zhang, W. Research on an Evaluation Method for the Job-Housing Spaces of Megacities Using Different Scales Based on Multisource Data Integration: A Case Study from Shenzhen. IOP Conf. Ser. Earth Environ. Sci. 2019, $264,012016$. [CrossRef]

37. Wu, Q.; Qian, L.; Wu, Z. Research on Spatial Structure Identification and Spatial Morphology of Megalopolis Based on Multisource Data. Geomat. World 2020, 27, 32-38.

38. He, D.; Liu, Y.; Liu, X.; Zhang, Z.; Zhou, J. Polycentric Spatial Structure Analysis of Mountainous Cities Based on Multi-Source Data- Polycentric Spatial Structure Analysis of Mountainous Cities Based on Multi-Source Data. J. Southwest Univ. 2019, 41, 73-81. [CrossRef]

39. Yang, L.; Hua, S.; Nan, J.; Ge, S.; Xin, C. The Evolution of the Urban Spatial Pattern in the Yangtze River Economic Belt: Based on Multi-Source Remote Sensing Data. Sustainability 2018, 10, 2733. [CrossRef]

40. Wu, X.; Lai, C. Study on Spatial Structure Characteristics of Urban Agglomeration Based on POI Big Data: Taking GuangdongHong Kong-Macao. Urban Insight 2019, 3, 44-55. [CrossRef]

41. Pan, B.; Wang, J.; Ge, Y.; Ma, M. Spatial Structure and Population Flow Analysis in Chengdu-Chongqing Urban Agglomeration based on Weibo Check-in Big Data. J. Geo-Inf. Sci. 2019, 21, 68-76. [CrossRef]

42. Wu, J.; He, S.; Peng, J.; Huang, X.; Zhang, L. Research on Spatial Characteristics of Urban Development Based on DMSP-OLS Data. Geogr. Geo-Inf. Sci. 2014, 30, 20-25. [CrossRef]

43. Gao, Z.; Tian, W.; Hou, J.; Wang, Y. Discussion on Urban "Micro" Renewal from the Perspective of Vulnerable Space: A Case Study of Erqi Dehua Block in Zhengzhou. Urban Dev. Stud. 2020, 27, 17-21.

44. Song, W. An Outlook of the Distribution Pattern of Urban Population in Henan in 2030. Econ. Surv. 2016, 33, 1-7. 
45. Li, X. Recognition of Urban Polycentric Structure Based on Spatial Aggregation Characteristics of POI Elements: A Case of Zhengzhou City. Acta Sci. Nat. Univ. Peking 2020, 56, 692-702. [CrossRef]

46. Zhang, J.; He, X.; Yuan, X. Research on the relationship between Urban economic development level and urban spatial structureA case study of two Chinese cities. PLoS ONE 2020, 15, e0235858. [CrossRef]

47. Chi, J.; Jiao, L.; Dong, T.; Gu, Y.; Ma, Y. Quantitative Identification and Visualization of Urban Functional Area Based on POI Data. J. Geomat. 2016, 41, 68-73. [CrossRef]

48. Chen, W.; Liu, L.; Liang, Y. Retail center recognition and spatial aggregation feature analysis of retail formats in Guangzhou based on POI data. Geogr. Res. 2016, 35, 703-716.

49. Zhao, X.; Du, H.; Zhao, P. Research on building database of urban POI based on normalization rules: Taking Jinan as a case study. Urban Geotech. Investig. Surv. 2013, 8, 21-24.

50. Alimujiang, K.; Tang, B.; Gulikezi, T. Analysis of the spatial-temporal dynamic changes of urban expansion in oasis of Xinjiang based on RS and GIS. J. Glaciol. Geocryol. 2013, 35, 1056-1064. [CrossRef]

51. Zhang, P.; Yang, D.; Qin, M.; Jing, W. Spatial heterogeneity analysis and driving forces exploring of built-up land development intensity in Chinese prefecture-level cities and implications for future urban land intensive use. Land Use Policy 2020, 99, 104958. [CrossRef] 